Article

\title{
Complexity Stage Model of the Medical Device Development Based on Economic Evaluation-MedDee
}

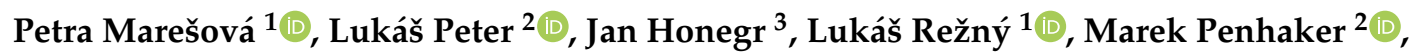 \\ Martin Augustýnek ${ }^{2}$, Hana Mohelská ${ }^{4}$, Blanka Klímová ${ }^{5}$ (D) and Kamil Kuča ${ }^{1, * \mathbb{D}}$ \\ 1 Department of Economics, University of Hradec Kralove, Rokitanskeho 62, 350003 Hradec Kralove, \\ Czech Republic; petra.maresova@uhk.cz (P.M.); lukas.rezny@uhk.cz (L.R.) \\ 2 Department of Cybernetics and Biomedical Engineering, VSB-Technical University of Ostrava, FEEC, \\ 17. Listopadu 15, 70833 Ostrava-Poruba, Czech Republic; lukas.peter@vsb.cz (L.P.); \\ marek.penhaker@vsb.cz (M.P.); martin.augustynek@vsb.cz (M.A.) \\ 3 Biomedical Research Centre, University Hospital Hradec Králové, Sokolská 581, 50005 Hradec Králové, \\ Czech Republic; jan.honegr@fnhk.cz \\ 4 Department of Management, University of Hradec Kralove, Rokitanskeho 62, 350003 Hradec Kralove, \\ Czech Republic; hana.mohelska@uhk.cz \\ 5 Department of Applied Linguistics, University of Hradec Kralove, Rokitanskeho 62, 350003 Hradec Kralove, \\ Czech Republic; blanka.klimova@uhk.cz \\ * Correspondence: kamil.kuca@uhk.cz
}

Received: 12 December 2019; Accepted: 23 February 2020; Published: 26 February 2020

check for updates

\begin{abstract}
The development of a new product is essential for the progress and success of any company. The medical device market is very specific, which is challenging. Therefore, this paper assesses an economic model for medical device evaluation using the economic, health, technology regulatory, and present market knowledge to enable the cost-time conception for any applicant. The purpose of this study is to propose a comprehensive stage model of the medical device development to subsequently describe the financial expenditure of the entire development process. The identification of critical steps was based on the literature review, and analysis, and a comparison of the available medical device development stages and directives. Furthermore, a preliminary assessment of the medical device development steps and procedures on the basis of the interviews was performed. Six interviews were conducted with an average duration of one hour, focusing on areas: relevance and level of detail of the medical device development stages, involvement of economic methods, and applicability of the proposed model. Subsequently, the improvement and modification of the medical device investment process, based on respondents' responses, were conducted. The authors have proposed the complexity model MedDee-Medical Devices Development by Economic Evaluation. This model is comprised of six phases: initiation, concept, design, production, final verification, and market disposition in which the economic methods are incorporated.
\end{abstract}

Keywords: medical device; development; economic evaluation; model; regulatory

\section{Introduction}

The development of a new product is essential for the progress and success of any company. This assertion is particularly true for the challenging medical device (MD) market. However, the development of the new MD is often uncertain and expensive [1,2]. Moreover, due to the innovation research required, $\mathrm{MD}$ development introduces many risks. Therefore, great attention is being paid to the evaluation of investment effectiveness into MDs [3]. Altogether, there are three main groups of 
methods: strategic and financial valuation of projects (e.g., Net Present Value (NPV), Internal Rate of Return (IRR), Discounted Cash Flow (DCF)); weighting and scoring of products and product criteria (e.g., analytic hierarchy process (AHP) and conjoint analysis); and human decision-making (fuzzy logic, actuarial models, neural networks, technology road mapping, and expert systems). As for the strategic and financial aspects, Vernon et al. [4] used NPV in order to establish maximum willingness to pay (WTP) based on criteria such as cost-effectiveness thresholds. Freiberg and Scholtz [5] proposed a discrete event simulation in order to determine the effectiveness of investment into technological development, based on calculations of NPV, IRR, and payback period. Kiliç and Kaya (2015) [6] used in their model, type-2 fuzzy AHP and type-2 fuzzy The Technique for Order of Preference by Similarity to Ideal Solution (TOPSIS). Finally, Vallejo-Torres et al. (2011) [7] used Bayesian methods, illustrating how these methods can be utilized to include all the data available at different development stages. While such models are necessary in order to give a clear structure to any complex development project which involves considerable resources and investments, the very complexity of these modeling approaches makes them difficult to apply in a real-life company environment. This obstacle to practical use was discussed by Money et al. [8], who devised a relatively simple spreadsheet-based tool intended to lead companies smoothly through the decision-making process and facilitate a common understanding between the companies and the NHS National Innovation Centre. Continuing in the effort to build a bridge between theory and practice, Ijzerman and Steuten [9] researched the question of how likely Health Technology Assesment (HTA) is to be utilized by development companies in the decision-making process. Surveys conducted in selected companies [10] suggest that among commonly used methods informing the decision-making, there are discounted cash flow (DCF), unstructured peer reviews, scoring checklists, and decision tree analyses. Bootman [11] pointed out the differences between the various types of economic evaluation, from cost-effectiveness analysis (CEA), through cost-utility analysis (CUA), to cost-benefit analysis (CBA). Danner et al. [12] characterize the analytical hierarchy process (AHP) as a multi-criterial analysis type which takes into account both qualitative and quantitative factors. Its drawbacks include possible confusions regarding the numerical scales used in the analysis, as their relationship with the verbal descriptions is not rooted in any theoretical foundation [10]. Furthermore, this method forces the decision-maker to choose always one decision from a given set of possible decisions, regardless of whether the decisions offered are acceptable at all.

In case they are used, the concept of fuzzy logic is abstract and requires an expert input. An expert system is an artificial intelligence technique that uses an input knowledge base and inference engine to solve a problem [13]. The knowledge base required by the system is time consuming, and it may be difficult for experts to express knowledge in terms of specific rules and confidence factors [10]. Moreover, the MD companies use a range of other methods to decide which new products are likely to result in good financial returns, including fewer tangible approaches such as a 'gut feeling' based on the experience in the marketplace [14].

Some of above-mentioned methods have problems regarding the specifics of the development of an MD [15]. In some cases, an important business reality is ignored. Projects rarely proceed as planned, and management frequently must adapt and revise future decisions as new information becomes available or as uncertainties are resolved. In the case of more complex methods, they can be as follows. First, people can become overly focused on the numerical precision of the calculations and the sophistication of the model, instead of on the quality or relevance of the data input into the model. Second, many managers may feel a little intimidated by the complexity of the techniques. Third, such tools require extra resources and are hence a luxury that only 'large' organizations may be able to afford.

The purpose of this study is to propose a comprehensive model of the MD development to subsequently discuss economic evaluation methods as a part of a relevant phase of medical device development process. The individual phases are described at a sufficient level of detail so that the idea of time or financial demands of each phase can be outlined. 


\section{Theoretical Background}

\subsection{Development Stages}

There is no uniform understanding of the number of phases and their content. For instance, Martin et al. [16] described an MD development lifecycle in these steps: identification of user needs, validation and refinement of the concept, device design, and device evaluation. Panescu [17] proposed these phases: funding, concept, development, verification and validation, product, and market release. Pietzsch et al. [18] suggested the following phases: initiation, formulation, design and development, final validation and product launch, and post-launch assessment.

The basis for the specification of the phases of the development of MD is a research study by our team [19] that describes different models differing in the number of specified phases, that is, in the range of 4 to 13 phases, where the contents are similar and sometimes differ from the viewpoint and the manner of processing. In the studies with a lower frequency of phases, tasks have often been found as a sub-task of one phase. Only the studies that address all the phases of the development of MD were selected for further analysis. These studies are as follows: [16,18,20-22]. Overall, their approach can be summarized in five steps (Figure 1), where each step contains the name of each author and the phases, the content should be similar. Only $[18,22]$ have differed from other research studies in combining the production of an MD or production and verification.

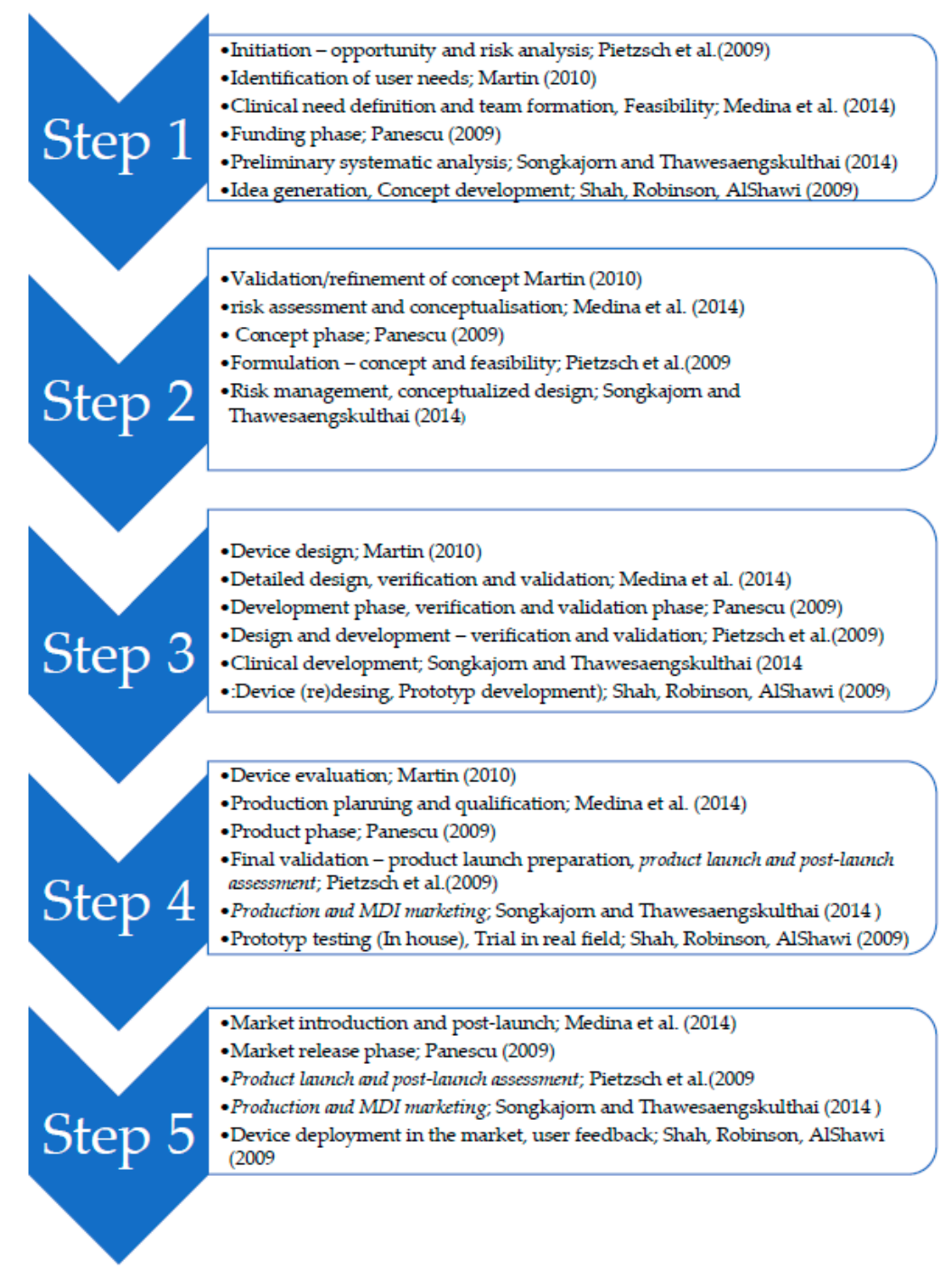

Figure 1. Review of Medical Device (MD) development stages. 
In terms of the purpose of this study, the findings of the aforementioned studies are considered as a starting point, but the steps of production and deployment are separate. Based on the aforementioned phases from individual authors, the following steps will be taken as a starting point for the development of MD:

Step1: Initiation

Step 2: Concept proposing

Step 3: Design and development

Step 4: Verification and validation

Step 5: Production

Step 6: Market device deployment

In the literature describing how companies function, many theoretical bases can be found. The problem is, however, that the actual functioning of the company is its know-how. The individual phases may differ due to theoretical assumptions, but this is due to the fact that the manufacturer only determines how $\mathrm{s} / \mathrm{he}$ will manage the business. In addition, only a few studies describe the stages of the development of medical devices in detail, most of which are very brief. Therefore, it is not clear how the individual phases could be priced and the development costs could be pointed out. Furthermore, the situation in the US is different from that in Europe, when the conditions for marketing change in Europe. This is also not addressed in the above studies. In addition, the authors aim to link the individual phases with their economic evaluation.

A survey of the current state of literature, descriptions, and economic models and a comparison with the actual processes in the company showed the possibility of extending and innovating the current approach concerning the economic models of the companies.

\subsection{Economic Evaluation Methods}

The studies can be divided into those using the classical economic indicators and those using the new age models.

The classic economic indicators involve the ratio indicators that assess the company's performance in terms of profitability, activity, debt, and liquidity. The ratio of relative growth is indicated by the elasticity indicators. The standard financial performance indicators include the absolute value of profit, cash flow (direct, indirect), and profitability indicators. The rate of return indicators assesses the ability of a company to make a profit by using invested capital. On the time axis, these indicators should manifest an increasing tendency. These indicators include return on assets (ROA), return on equity (ROE), return on sales (ROS), and return on capital employed (ROCE). The traditional indicators are an integral part of the evaluation of a company's performance, but they are subject to criticism because they do not take into account the risk, the effect of inflation, and the time value of money. Most of these classic indicators are based on accounting data and in particular, on the company's economic results. The weaknesses of the financial analysis make the results less valuable and less useful.

Since the 1980s, performance has begun to be viewed as the ability to create value for owners. The major aspects of performance, also the time aspect with respect to expectations of future profits, as well as the very important influence of risk. Increasingly important are also the indicators of economic value added (EVA), discounted cash flow (DCF), market value added (MVA), excess return (ER), and total shareholder return (TSR), which are indicators that take into account the goals of other interested parties, i.e., stakeholders. The new indicators already take into account the impact of inflation, risk, and the cost of capital.

Finally, the third and last group is known as new age methods, which are characteristically highly complex but also very specific, hence more efficient, and tend to work with a robust set of data. Korol and Kolodi [23] proposed a fuzzy logic model that uses dynamic financial ratios as input. Sun, Shang et al. [24] worked with the imbalanced financial distress prediction (FDP) based on support vector machine (SVM) in order to increase the efficiency of the approach as per an imbalanced dataset. 
Currently, the most widely used approach is HTA, designed for use specifically in the field of health technologies. This method sets out standards for safety, efficiency, and cost effectiveness in evaluating medical device development. HTA purports to provide a framework for decision-making on national, regional, institutional, and individual levels. Despite the usefulness of this framework, there still remains a challenge of how to adequately evaluate the effectiveness of the technology in question.

The literature has suggested that the most common economic method used in the economic evaluation of the MD development is the cost-utility analysis [25-28], followed by the cost-effectiveness analysis [26,29], and the cost-consequence analysis [27,29]. These findings are consistent with other studies on this topic $[30,31]$. From the point of view of economic indicators, they are a normal component of the profitability, profit, or costs of the ownership ratio. These include, in particular, return on investment (ROI) and total cost of ownership.

Formulas for methods with very frequent occurrence in the case studies on the evaluation of medical, the evaluation of investments, or utilization in the sphere of healthcare are illustrated in Table 1.

Table 1. Methods used in the case studies on the evaluation of MD.

\begin{tabular}{ll}
\hline \multicolumn{1}{c}{ Purpose } & \multicolumn{1}{c}{ Indicator, Type of Analysis } \\
\hline $\begin{array}{l}\text { Evaluation of benefits, typically only for technologies } \\
\text { where the impact on human health and required by } \\
\text { legislation is measured. }\end{array}$ & $\begin{array}{l}\text { QALY is the combination of quantity and quality of } \\
\text { life generated by an intervention; One QALY = 1 year } \\
\text { of perfect health, numerically compare the benefit } \\
\text { gained from a variety of interventions. }\end{array}$ \\
\hline $\begin{array}{l}\text { Comparison of two solutions in terms of costs for one } \\
\text { year of QALY. }\end{array}$ & $\begin{array}{l}\text { ICER (Calculates the cost to generate one additional } \\
\text { year of perfect (one QALY) health if using } \\
\text { intervention B in place of intervention A). }\end{array}$ \\
\hline
\end{tabular}

This is important with respect to the decision of whether to start the investment.

Industry and investors seeking informed product development decisions based on health technology assessment; marketing managers seeking to differentiate products based on cost-effectiveness; sales managers seeking to articulate the value proposition of innovative products; R\&D managers wishing to integrate health economic considerations into new product development systems

\begin{tabular}{ll}
\hline Economic indicators in CEA or CBA [35,36] & $\begin{array}{l}\text { average annual costs } \\
\text { discounted costs } \\
\text { net present value and profitability index } \\
\text { internal yield percentage } \\
\text { average return (yield) } \\
\text { payback time }\end{array}$ \\
\hline $\begin{array}{l}\text { Cost benefit analysis (CBA)_Transformed to } \\
\text { (measured in) money units (e.g., CZK, EUR, USD); }\end{array}$ \\
$\begin{array}{ll}\text { Cost-effectiveness analysis (CEA)_Expressed as one } \\
\text { figure in natural units (e.g., number of life-years } \\
\text { saved, incidence of the disease); } \\
\text { Cost-utility analysis (CUA)-Expressed in QALYs } \\
\text { (i.e., quality-adjusted life-years); } \\
\text { Cost-consequence analysis (CCA)-Listed in } \\
\text { natural units. }\end{array}$ \\
\hline
\end{tabular}

\subsection{Legislative Environment}

In May 2017, the EU Medical Devices Regulation (MDR) passed by the European Parliament, gave the companies in the MedTech industry from 3 to 5 years to fulfill the compliance criteria set by the regulation, including establishing new procedures for the marketing approval of newly developed 
products and a reauthorization of the products, already available on the internal market. The goal of the new regulation was to bring the field of MDs closer to the standards of safety set by the pharmaceutical industry and to renew trust in the MedTech industry after the high-profile breast implant scandal and hip replacement failures. The main change in the regulatory framework is the focus on safety, which is to be achieved by strict processes leading to the market authorization and declaration of conformity and obtaining CE marking. The MedTech companies must implement new quality assurance standards to introduce the unique device identification which allows authorities to trace individual devices through the supply chain and simplify recalls in case of emergency situations. The Medtech companies will have to create the position of a person responsible for regulatory compliance, similar to the pharmaceutical industry qualified person, who is responsible for all the aspects of compliance with MDR.

Moreover, to obtain the MDR authorization for class III and implantable devices, the MedTech companies will be required to present a notified body with a large volume of clinical data that supports the clinical performance of their products. Another key factor is the monitoring of device performance by post-marketing surveillance, similar to the processes used by the pharmaceutical industry [37]. An additional aspect is a focus on the strict scrutiny applied to the European notified bodies (NBs). All NBs will have to apply for a joint audit undertaken by a local competent authority, another member state competent authority, and European Commission representative and must demonstrate proficiency in and adherence to quality management systems.

This stricter scrutiny is leading to a decline in such entities. Under the previous medical devices directives (MDD), there were over 80 NBs. The number declined to circa 50 in October 2017, and as of 1st of January 2020 (fewer than 150 days to the date of application of MDR), there are only 9 notified bodies already accredited according to MDR and further reduction is anticipated [38]. In December 2019, the second corrigendum to the MDR was approved, which granted a transient period for newly established classes Is (sterile), Ir (reusable), and Im (with measuring function) devices, allowing manufacturers and NB to focus more on the recertification of higher class products. But there is still a great threat to the Small and Medium sized Enterprises manufacturing legacy devices, which stems from the provision of MDR that banish grandfathering of devices approved under the MDD, without providing sufficient clinical data for conformity assessment process.

The major problem from the MDR implementation is in the field of innovation. The majority of innovative research in the field of MDs is not undertaken by big companies but depends on the smallto medium-sized enterprises (SMEs), which stems from a cooperation of healthcare professionals with their local "garage" companies or off-spin labs of universities. There are about 25,000 MedTech enterprises in Europe, and 95\% of them are SMEs [39,40]. These types of enterprises are at the greatest risk of leaving the market because the administrative costs will be almost unbearable for them. Such companies are usually focused on the production of a small number of products, and their margin does not allow them to pay for all the necessary costs connected with the compliance to MDR. The estimated costs for the small- to medium-sized enterprises to launch a new class III MD will be between EUR 1 and 4 million or EUR 7 to 28 million if the device must fulfill the requirements of the centralized pre-market authorization procedure. The more serious scrutiny will affect approximately $10 \%$ to $20 \%$ of class III products [40]. In the near future, a diminishing portfolio of available MDs would be observed, especially in the field of lifesaving implants or generally class III devices. It will follow from the stakeholders' reluctance to large-scale investment to ensure the compliance with MDR, when assessment may predict that the investment in such technology may not pay off on future product sales. This will lead to the orphaning of some groups of patients, some with critical conditions. In this particular field, measures similar to the Orphan Drug Regulation (Regulation (Ec) No 141/2000 Of The European Parliament And Of The Council of 16 December 1999, on orphan medicinal products) for MD development, which establish stimulations for their research, development, and marketing, should be implemented. 


\section{Methods}

The study design is based on two main steps. The first step is to analyze and compare the available steps of the development of MD to set a basis for the phases of the medical device development that will be appraised later as part of the economic methods [41]. In addition, the model design and its verification will be performed.

\subsection{Analysis and Comparison of Available MD Development Phases and Investment Evaluation Methods}

In the beginning, the identification of critical steps was based on the analysis and comparison of the available medical device development stages in the professional studies to set the basis for the development of MD [19], which will be appraised later as part of the economic methods.

\subsection{Evaluation of the Stage Investment Model}

The following steps must be conducted to develop, revise, and improve the suggested MD investment model:

(a) The preliminary assessment of the MD investment practices and procedures from seven interviewees who actively cooperate with researchers (5) and companies (2).

(b) The detection of the team members involved in the evaluation of prospective investments.

The authors conducted close qualitative interviews because of the broad variety of activities involved in the MD development process. The survey questionnaire for the complex background of eight questions was sent to seven experts experienced in the MD development process. There was a follow-up, 1-hour, long-distance interview. The questionnaire consisted of multiple choice YES or NO questions that explored the validity of linking a few engineering and management features during the design optimization. In addition, the options of low, medium, and high were provided to obtain insight into the feasibility of the combination of engineering and product development features.

The semi-structured face-to-face interviews with employees of the Top management are one of the basic sources of information for a comprehensive evaluation of return on investment in the MD development. The interview questionnaire was based on the principles of intervention logic [42] and contained 12 evaluation questions. The interviewers asked the respondents according to the prepared questionnaire and usually asked further questions, which expanded and supplemented the range of monitored problems. The draft of the questionnaire was commented within the project team and cooperated research from other Czech universities who actively develop medical devices at their workplaces. The interviews with the TOP management staff began in February 2019 and ended in March 2019. A total of six interviews were conducted. The interviews were conducted in two companies Ella-CS, Ltd., Tesla Medical and Mediatrade Ltd. with people in the position of business owner, executive director, sales representative, development director, head of economic department, regulatory expert. The interviews were conducted by 1-2 experienced members of the evaluation team and a written record was made from each interview into the prepared record sheet. The respondents responded willingly and honestly, and in many cases, they supported their comments with a number of facts and information.

Criteria for selecting experts was based on the professional background they have in the field of medical devices and in relation to their present competencies. In terms of model and verification/evaluation of its purpose in business practice in the context of the company's vision and strategy, the company owners were selected. For discussion and determination of involved economic methods and their suitability-head of economic department. The development director and regulatory expert were then asked to evaluate the relevance of the specification of the stages of medical device development. Sales representative and executive director were chosen to verify clarity and the possibility of transferring the model to types of medical devices and different markets.

It was one woman (head of economic department) and five men. The interview took place in Czech. In the first case, it took place in the seat of Ella-CS, Ltd., in the second case it was held at the University 
of Hradec Kralove. The logic of the interpretation of the interview results is organized according to the approved concept of evaluation questions and the results from the analysis of respondents' answers were assigned. The evaluation questions and subsequently, the evaluation of the whole interview was divided into six thematic blocks.

(1) Description of the process-the first block of questions focused on the fact of how the processes of the medical device development are set up and registered, whether there is a methodology in the company, how and for whom it is available, to which stages they divide processes, what the level of completion is, what partial actions are cost-related, and to what extent details.

(2) Impact of the affected technology on the process-in the next stage, more attention was paid to the differences in the risk class of the medical device. The questions again concerned the development of the medical device, the linking of the development phases of the medical device to the risk class (I, II, III) (Table A1) and the associated costs; legislative changes awaiting the Czech Republic-transition to the new MDR of the European Commission, what it means for companies, what strategy they are considering.

(3) Evaluation of the investment effects on the process-the third block of questions focused on variants/ business models and target groups.

(4) Investment costs.

(5) Potential cost savings and potential risks.

(6) Calculation of return-use of financial indicators by companies and their involvement in the development of medical devices (types of financial indicators, the time of product on the market is/is not taken into account, or involvement of qualitative factors such as loss of novelty).

The assessment and improvement of the proposed model were performed on the basis of the provided feedback from the respondents. This process was performed in the form of proposals and appeals for change. If there were appeals for smaller modifications, they were conducted immediately in each phase to be once again evaluated by the interviewees. If there were serious appeals for change, they were conducted after the completion of each phase and upon the mutual agreement among the respondents. If there were no appeals for change, the interviewees were asked to confirm a full agreement with the presented model. The results of the interviews are in addition to the time-consuming steps to better illustrate the concept of the activities. Upon the improvement and modification of the MD investment process, a quick pre-assessment checklist was developed on the basis of the respondents' responses. Although this checklist was not the primary goal, it can form an auxiliary instrument, potentially valuable for new life-science investors. The interviews followed the aforementioned methodology and were mainly based on [18]. Nevertheless, the authors of this study adjusted it to develop a framework, especially useful for the investors.

\section{Results}

\subsection{Phases and Processes of the Model of the Medical Device Development}

First, all phases related to the specifics of the development of MDs and their investment are reflected in the formula for calculating the economic indicators; then, the required investment efficiency can be assessed. The starting points are therefore initiation, concept proposing, design and development, verification and validation, production and market device deployment. The complexity model for the economic evaluation of MDs was established as the Model of the Medical Device Development based on Economic Evaluation (MedDee).

The above-mentioned setting of the stages of development of medical devices is based on mapping the current state of knowledge and knowledge from business practice in the Czech Republic. Based on the theoretical background, the initial model was designed and phases of the model were designed. After the interviews were conducted, feedback and information on the suitability of the set phases were obtained. Furthermore, information was needed on the need to specify a certain level of detail, so that it did not affect the differences that relate to different types of medical devices. Information 
was therefore obtained on the appropriateness of the level of detail, the phases, the involvement of economic methods, the sustainability of the method in the context of changing legislative conditions. Regulatory experts have also helped illustrate the changes that will affect companies in the coming years and how they should affect the ideals of medical device development.

For example, the chief executive of a selected company stated, "at each stage of the development process, the cost estimates are being refined and the next steps are adjusted. At each stage, it is again decided whether or not the development continues. Therefore, the cost of a person registering partial activities under the methodology must be taken into account at each stage".

Regarding regulatory, the responsible person states "it will be crucial in the future to adjust the methods and the possibility of automatic cost consideration at the time of product launch, when clinical trials and more will be needed in selected risk classes".

The responsible person for the economic part also stated that within the company, they count on "about a 3\% decrease in the value of the product in the post-market time and is always taken into account in our calculations".

Findings from interview are therefore reflected in the phases specified below.

\subsubsection{Initiation}

In the first initiation phase of MedDee, the customer's needs are identified, as well as the answer to the question: "Is my product a MD?" "Part of this stage is also the initial description of the functionality and intended use, the benefit compared with the existing solutions, the analysis of competing products, the initial estimate of development costs (including directive), revenues, and financing", said the development director during the interview.

The verification of the formerly detected clinical needs may include discussions with doctors, end-users, or patients. Furthermore, this stage comprises a review of the existing MDs and procedures. Other activities that must be considered are as follows: an initial market analysis, financial review, and competitive product evaluation. The reviews of the existing IP landscape within a specific market or pathology area and technology risk evaluation are performed.

As it has been mentioned before, the first of the input parameters must be to integrate the product into a group according to a specific rule. Table 1 describes how the individual rules are passed between the classes. The list of codes and corresponding types of devices for the purpose of specifying the scope of the designation as NBs in the field of medical devices under Regulation (EU) MDR 2017/745 [43] are as follows:

- Active implantable devices;

- Active non-implantable devices for imaging, monitoring and/or diagnosis;

- Active non-implantable therapeutic devices and general active non-implantable devices;

- Non-active implants and long-term surgically invasive devices;

- Non-active, non-implantable devices;

- Specifics of MDs;

- Technologies for MDs-auditing.

This division does not depend on the risk class. The medical device regulation divides MDs into classes I, Is, Im, Ir, IIa, IIb, and III and a special category of custom-made medical devices, taking into account the intended purpose and risk (Table 2). The MDR classification system does not radically differ from the MDD, although it is better to consider the level of invasiveness and level of toxicity. Some new rules were added. The classification rules, which are based on the vulnerability of the human body, should take into account the potential risks associated with the technical design and manufacturing of the devices [43]. 
Table 2. Relation of the MD types and classification rules.

\begin{tabular}{|c|c|}
\hline MD according to the Risk & Classification Rules \\
\hline $\begin{array}{l}\text { Class I-“Provided all of low risk medical devices (class I) or sterile } \\
\text { (class Is) and/or have a measuring function (low/medium risk class } \\
\text { Im) or reusable low risk devices (Class Ir), which are placed on the } \\
\text { market in sterile condition, have a measuring function or are } \\
\text { reusable surgical instruments: Assessment of the technical } \\
\text { documentation relating only to those specific features of the device, } \\
\text { e.g., sterility, measurement or reprocessing." }\end{array}$ & Rules: $1-2,4-6,10-11,13$ \\
\hline $\begin{array}{l}\text { Class IIa (medium risk) Class IIa devices: "Assessment of the } \\
\text { technical documentation for at least one representative device for } \\
\text { each category of devices". }\end{array}$ & Rules: $2-8,10-12,17,19-21$ \\
\hline $\begin{array}{l}\text { Class IIb (medium/high risk) Class IIb "implantable devices (except } \\
\text { sutures, staples, dental filings, dental braces, tooth crowns, screws, } \\
\text { wedges, plates, wires, pins, clips and connectors), and class IIb active } \\
\text { devices intended to administer and/or remove a medicinal product: } \\
\text { Assessment of the technical documentation for every device. All } \\
\text { other class IIb devices: Assessment of the technical documentation } \\
\text { for at least one representative device per generic device group". }\end{array}$ & Rules: 2-12, 15-16, 19-21 \\
\hline $\begin{array}{l}\text { Class III (high risk) Class III devices: "Assessment of the technical } \\
\text { documentation for every device". }\end{array}$ & Rules: $2-3,6-9,14-15,18-22$ \\
\hline
\end{tabular}

Note: Full text of the rules in Appendix A, Source: Based on [43].

Already in the first phase, an initial economic evaluation of the planned development was to be designed and carried out. It should be done as follows:

- $\quad$ setting an appropriate time horizon for the economic evaluation;

- identification of all types of resources needed for the use of technology and comparators;

- calculation of the unit costs of each resource and the total costs of public health insurance and;

- $\quad$ costs from a societal perspective;

- $\quad$ indicate the costs that have implications for non-medical budgets (generally social costs).

\subsubsection{Concept Proposal}

The second stage of MedDee consists of a design and development plan; a product specification; its functions, size, material, packaging, and production concept; and a schedule and implementation team. A cross-functional team is set up to formulate a concept, assess device feasibility, and develop a design plan and a timeline of the whole project. The team consists of the principal experts of R\&D, quality assurance, production, marketing/sales, regulatory, clinical, and legal entities.

In terms of specific activities, the design requirements plan, product requirement specification, production concept, project plan, risk management plan, clinical evaluation concept and post-marketing clinical follow up (PMCF), business registration plan requirements, and personnel assurance requirements are often developed.

At this stage, the CEA or CBA method should already be carefully elaborated so that it is clear what costs and especially the benefits, which can often be of a qualitative nature, can be expected and how they will be translated into financial statements. These data should be continuously updated in the next stages to provide a complete basis for the development of the HTA at the end of development, as it is likely to be mandatory in most EU countries in the coming years. The calculations and their updates shall provide evidence for:

For which disease/health problem/potential health problem the technology should be used. Experts in the field of business evaluation should answer questions such as:

How is the disease/ health problem is currently diagnosed, how is it treated, how should it be diagnosed and treated according to the published procedures, what are the other alternatives 
to the technology in question, and what are the differences in the treatment of the disease in their different phases?

How will the use of technology affect the overall quality of life?

What are the risks of using the technologies, their frequency, severity and duration, dose-related or cumulative-dose relationship?

What is the investment needed to use the technology in question, what extra space, what other equipment and supplies are needed? What type of data records is required to track the use of technology and what registers are needed to monitor its use?

\subsubsection{Design and Development}

After the activities performed in Phase 2, the product is ready for the conversion-from concept to development. The market opportunity is already identified. In terms of both regulators and the IRP, risks are acceptable. The MD has a specified class and is included in the company strategy. During this stage, the verification and validation tests before and after the design freeze Phases III and IV of MedDee are performed. The verification and validation studies including their methods of documentation are checked. The proper documentation is a must from a regulatory perspective because all scientific studies must be reproducible. The patent review process also persists in Phase III, or even in Phase II. The reimbursement policy of the MD is set in Phase III, because reimbursement codes and part numbers are assigned to the new device.

"The activities connected with the design are as follows", said the development director:

- "Product design, design verification, and validation (determination of the tests to be carried out before and after the design freeze).

- Regulatory-verification of the protection of the technology, and possibly specification of accompanying documentation".

The activities connected with the development are as follows:

- Purchase and validation strategy (technical solutions to fulfil customer requirements, specification of all key parameters' specifications, design of production technologies, materials design, supplier decisions).

- $\quad$ Regulatory (post market clinical follow up (PMCF) plan, post-performance qualification, clinical evaluation plan).

- Risk management design failure mode and effects analysis (dFMEA), update advanced failure modes and effects analysis (aFMEA).

- Technical specifications, block diagram, eclectic diagram, detailed design hardware(HW), software (SW), mechanical design, prototype.

- $\quad$ Testing.

The individual tests, their time requirements, and the price vary according to the safety class and MD type (Table 3).

Electromagnetic compatibility according to IEC 60601-1-2 is measured in accredited laboratories in three steps: electrical resistance, radiation, and electrostatic charge. The tests are not demanding; however, they can last up to 1 year if one of the tests fails. Then, the manufacturer has to modify his/her prototype or existing product until it passes the test. Otherwise, at the next supervisory audit, $\mathrm{s} /$ he loses the certificate and the CE mark. This is an electrical MD. The verification of safety (electrical safety) according to IEC 60601-1-1 and any other standards standardized for the type of MD (fans, neuro-stimulators, pacemakers, . . . all from the IEC 60601-2 series of standards) is performed. The tests are performed, respective measurements, which should confirm that if the manufacturer has a value of 30 at the output, it should be true. Many tests are measured by the testing facility by its devices, which the manufacturer carries out only for his/her MD. The tests can last for up to 1 year: the MD is tested and everything is compared with the documentation: manual, risk analysis, 
and usability. Therefore, the testing sometimes takes a long time. Most commonly, a type test is conducted to confirm the safety of the product. The manufacturer performs this test or performs this test under electrical safety. The manufacturer conducts this test to ensure that when the device is in the test room, everything will work. For these tests, it is necessary to provide a measuring device to create conditions that can be possibly applied at the output inspection and test each device before it is sold. The test can be conducted within 1 or 2 months by the company. In addition, a biological evaluation, the safety assessment of the product according to ISO 10993, is conducted. This includes tests in laboratories to determine if the MD is biologically safe for the patient. The three basic tests are cytotoxicity, sensitization, and irritation. The sensitization, like delayed irritation, is tested for 1 or 2 months. In the beginning, a preclinical evaluation is required to demonstrate its state of the art along with the underlying theory. This document has to prove that the intended principle is safe, at least theoretically. Further extent of clinical evaluation is established based on this document; if a similar MD is already on the market, a clinical trial may be conducted or similarity can be assessed, or the clinical data may be evaluated. When it is a completely new method, the whole preclinical (laboratory, animal model) and clinical evaluation must be conducted. This process may take 1 to 2 years, according to the number of patients, the complexity of the method, or the principle. Once all the tests are completed, the results are processed and applied to the clinical evaluation with the information describing the clinical relevance of the MD. After that, this information is passed to the specialist, the clinician, or the general practitioner who reads it, evaluates it, and writes or signs the final clinical trial report. This report is attached to the conformity assessment. The processing of all documentation without clinical trials lasts for about 90 days. As aforementioned, a more precise specification of activities is then linked to a specific type of MD.

Table 3. Examples of the time-consuming mandatory tests for class IIb of MD.

\begin{tabular}{ccc}
\hline TESTING ${ }^{1}$ & TIME & PRICE \\
\hline EMC & 90 days & EUR 5200 \\
\hline Electrical safety & 180 days & EUR 6000 \\
\hline Type test & 180 days & EUR 6000 \\
\hline Biological evaluation & $90-120$ days & EUR 10,000 \\
\hline Preclinical evaluation & 40 days & EUR 2000 (worker's salary per 2 months) \\
\hline Clinical evaluation & Up to 360 days & $\begin{array}{c}\text { CZK 50,000-10,000 (annual clinical trial, 100 } \\
\text { patients, device IIa, CZK 8 mil., in the case of a } \\
\text { clinical trial based on the use of its own clinical } \\
\text { data, CZK 50,000 per worker's salary for 2 months) }\end{array}$ \\
\hline
\end{tabular}

\begin{tabular}{ccc} 
Verification and validation $\quad 60$ days & CZK 60,000 \\
\hline Note: ${ }^{1}:$ Average time and money for class IIb, case study based on the conditions for the Czech Republic.
\end{tabular}

\subsubsection{Verification and Validation}

Phase IV of MedDee is characterized by the creation of formal design prints, final product verification and validation, sales launch preparation, and regulatory approval. Most of the steps from Phase III continues and is completed. Material specifications, packaging drawings, and marking and labelling specifications are finalized, and several sales and marketing activities must occur prior to the launch of a new MD. In addition, all of the aforementioned electrical safety and Electromagnetic Compatibility (EMC) tests are conducted. The price and time may vary, depending on whether the device has been tested earlier in the laboratory, or whether it is a brand-new type, or whether it is the same type from a generic range of products that just has a display instead of a button.

Another key process is the conformity assessment process, which is one of the necessary conditions for placing a product on the market and can be generally labelled as a sequence of operations in a unique structure for a particular product group. The conformity assessment procedures are divisible to 
modules related to the product design phase and the manufacturing phase, and the product is generally assessed in both of these phases. Sometimes, the assessment can already start in Phase II. Basic modules can be used in multiple phases, in relation to a given product group. Clinical evaluation can be made as an essential equivalence between devices. The conformity assessment process, including the EC declaration of conformity or other related procedures, needs not be performed by the importer for products bearing the CE mark and for which a demonstrable conformity assessment has been carried out in accordance with the relevant technical legislation of the EU Member State. The time and financial demands for a selected group of MDs in the Czech Republic are shown in Table 4 and are compared with the data of the US consultant group Emergo by UL, which estimates costs for the approval for the US companies.

Table 4. Time and financial demands of the conformity assessment process (expert's estimation of prices and conditions of the Czech Republic) compared to Emergo by UL estimates for the US customers.

\begin{tabular}{ccccc}
\hline Conformity Assessment & Time & Price & Complexity & Price \\
\hline & & CZE Estimate & & US estimate \\
Class I & & & 1 & EUR 4500-13500 \\
Class Ir, Is, Im & \multirow{2}{*}{360 days } & EUR 6000 & 2 & EUR 13,500-27,000 \\
Class IIa & & & 3 & EUR 27,000-45,000 \\
Class IIb & \multirow{2}{*}{480 days } & EUR 14,000-20,000 & 4 & EUR 45,000+ \\
Class III & & & 5 & EUR 45,000+ \\
\hline
\end{tabular}

It should be noted that both estimations presume that the manufacturer has the quality management system (QMS) already in place and validated and did not take into account cost associated with its maintenance, because it is considered as a fixed cost for a manufacturer.

\subsubsection{Production}

"In the production phase of MedDee, it is essential to verify the status of all the activities carried out so far", said the development director. In the area of risk, it is a review of the timeliness of the risk plan, the dFMEA update, the aFMEA update, a design verification report, and a design validation report. Furthermore, in the regulatory field, a review of accompanying documentation, acceptance of accompanying documentation, and application for the CE marking is carried out. At the end of this phase, it is verified that the product fulfils the customer requirements, regulators, and IPR and is ready for the release on the market. The risk management process has already been reviewed, and dFMEA and pFMEA are accepted. Additionally, the application for the CE marking has been filed. Once awarded, the mark is sent to the national authority, the national administration body that registers these types of MDs. The application for the conformity assessment has also been submitted.

In this phase, the early health technology assessment has been suggested in the context of iterative economic evaluation alongside phase I and II clinical research to provide information about clinical trial design, market access, and pricing [9]. Within its framework, the results should be calculated based on:

- determination of all direct and indirect costs for the rated technology and comparators, a summary of the costs related to public health insurance;

- benefits for the rated technology and comparators;

- $\quad$ the resulting ICER value in terms of the costs of the public health insurance payer and then also of the society-wide perspective, taking into account all direct and indirect costs;

- $\quad$ direct costs of the patient and his/her family (out of pocket money, co-payments). Although these costs are included in the ICER calculation from a societal perspective, their amount may influence the decision on the cost-effectiveness of the technology or the amount of the patient's supplement;

- $\quad$ sensitivity analyzes. 


\subsubsection{Market Device Deployment}

As part of the last step of the product deployment, the marketing objectives set out in the business plans must be monitored, with market launches. The post-market surveillance (PMS) and post-market clinical follow-up (PMCF) studies are available. Terrain and production data are collected and evaluated. Feedback from physicians and a vigilance system are already set, that is, follow-up and reporting of adverse events and the post-marketing follow-up process, which should regulate clinical evaluation and risk analysis and improve and optimize the product. But when it comes to the effective adjustment, the main benefit of PMS is that if the manufacturer knows, or at least has an idea of what to focus on, clinical trials can be skipped in the future. The clinical trials are the equivalent of clinical data, and the manufacturer can acquire them thanks to the properly configured PMS processes while selling his/her product on the market.

From the point of view of the development stages of the medical device, the role of the user is becoming increasingly important for several reasons; firstly, in the development phase, where, due to the competitive environment, manufacturers must know and take into account their needs from the start, and secondly, in the development and marketing phase, where clinical safety testing will be part of the new legislation. At the moment it can be stated that the inclusion of users in the development of medical devices is gaining in importance. Thus, it can be stated that involving users is limited or underreported in the published literature. This underreporting could be due to either commercial confidentiality or indeed a failure to recognize the importance of users as a whole. In addition, the limited practice of involving users could be due to the financial and time constraints, which manufacturers face, as well as a tradition of discretionary involvement of users [21,44].

The overview of the phases and the activities described is shown in Table 5. Many activities throughout the development process are performed simultaneously. Setting up a system description is independent of the production of the technical documentation that develops to the moment of submission to the notified body for the conformity assessment. The product launch time in the case of electrical MD, design, and development up to a functional prototype can take up to 2 years, at least, including laboratory tests.

As there are certain types of costs incurred at each step of the development of health-care products, while further development steps are being refined, the effectiveness of development is continually tested. Therefore, it is essential to use and match economic methods including benefits for patients, as it is currently anchored in the development of new drugs. The introduction of the HTA method as a compulsory part of the medical device assessment is discussed at the pan-European level.

\subsection{Economic Methods of Investment Efficiency Evaluation for Individual Stages of MD Development}

Each stage of development includes verification and ongoing review of investment effectiveness, specifying the return on investment calculation and ongoing verification of the decision to market the product in relation to a specific business model. Table 6 describes the methods at each stage, the economic indicators included in the selected methods, and the link to the stage where it is appropriate to specify the calculation.

The integration of complex methods into the individual stages of MD development and their updating is a time-consuming activity, however, in relation to the changing legislative environment, it is likely to be a necessary or even mandatory part in the future. 
Table 5. Phases of MD development and activities in all phases.

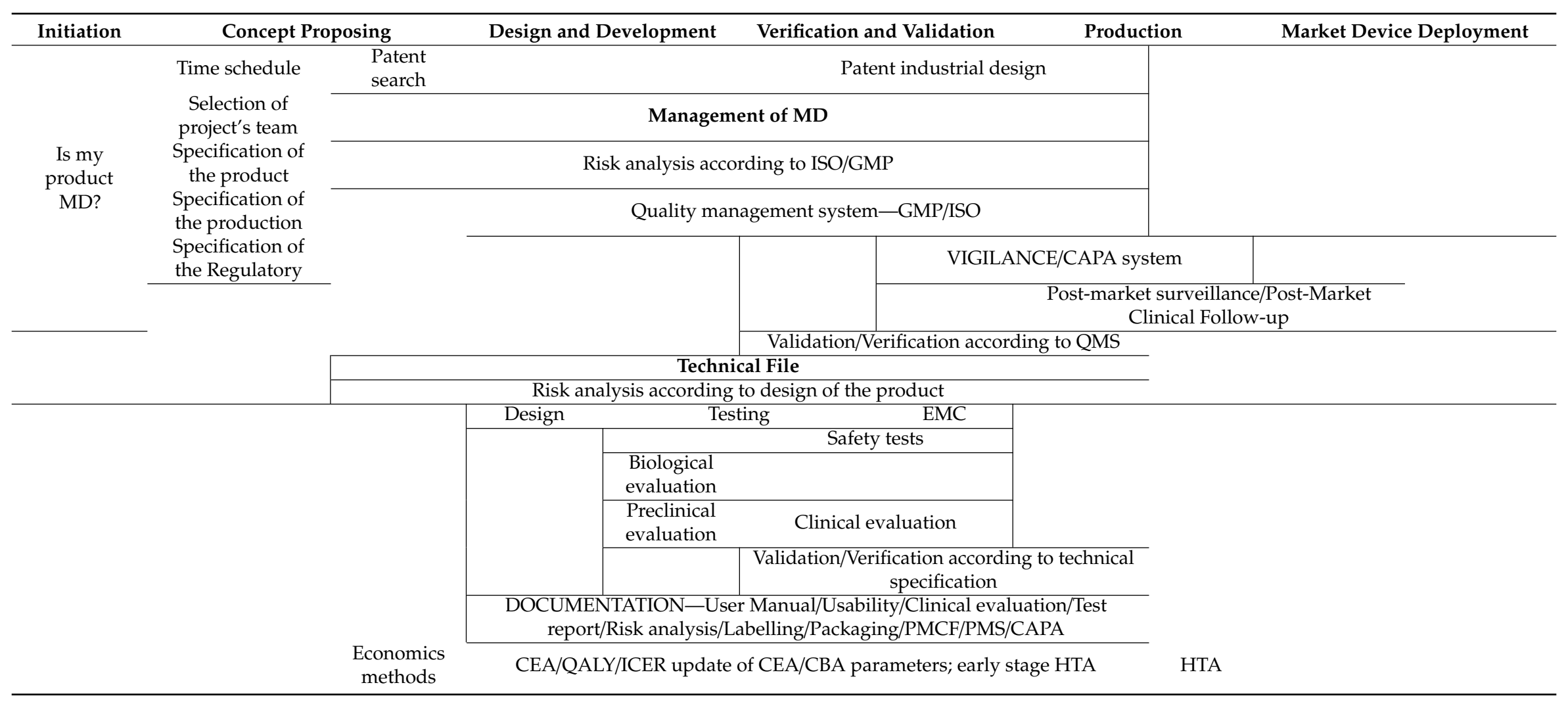


Table 6. Proposal of the intersection of the development stages of medical devices and economic methods for the continuous evaluation of investment efficiency.

\begin{tabular}{|c|c|}
\hline Phase & Economic Methods \\
\hline Initiation & $\begin{array}{l}\text { Comparison of the current situation and the new solution, } \\
\text { specification of all benefits and costs, within the general CBA } \\
\text { method, transfer of qualitative benefits to quantitative expression } \\
\text { (substitute market methods, shadow prices, hedonic prices, labor } \\
\text { market analysis. } \\
\text { Depending on the type of medical device (if relevant), a more } \\
\text { specific CEA method may be considered. A cost-effectiveness } \\
\text { analysis, especially for higher risk classes, should include one } \\
\text { QALY calculation, i.e., health if using new intervention/ new } \\
\text { technology in place of the original technology. } \\
\text { This is a period of preparatory work in which the project is being } \\
\text { prepared and decides on its implementation or rejection. In terms } \\
\text { of cash flows, this usually includes the costs of project } \\
\text { documentation, administrative costs of project preparation, costs } \\
\text { of processing economic studies, and costs of evaluating the } \\
\text { effectiveness of the investment plan itself. } \\
\text { The content of this phase is in any case the initial calculation of } \\
\text { dynamic and static economic indicators as part of the CBA. } \\
\text { In the case of instrumentation (i.e., risk class III), it is advisable to } \\
\text { use the HTA concept, which includes the assessment of societal } \\
\text { impacts, i.e., the CBA method. }\end{array}$ \\
\hline $\begin{array}{l}\text { Concept proposing } \\
\text { Design and development } \\
\text { Verification and validation } \\
\text { Production }\end{array}$ & $\begin{array}{l}\text { Update of benefits and costs, conversion to financial statements, } \\
\text { use of economic indicators: average annual costs, discounted costs, } \\
\text { net present value and profitability index, internal rate of return, } \\
\text { average profitability (return), payback period. }\end{array}$ \\
\hline Market device deployment & $\begin{array}{l}\text { Final HTA/ CBA calculation with real cost information. } \\
\text { Calculation of sensitivity analysis to identify cash flow scenarios } \\
\text { where its approach may be as follows: characterization of factors } \\
\text { affecting cash flows, change of each factor by a certain percentage } \\
\text { and for each change separately calculation of new indicator value, } \\
\text { calculation of change of resulting criterion indicator. }\end{array}$ \\
\hline
\end{tabular}

At present, in many European countries, health technology assessments are often carried out at a late stage of its life cycle, only 5-10 years after the product has entered the market, which may be irrelevant to the health system. This suggests that it would be appropriate to focus on the evaluation of the device in the early stages, i.e., in the first years since the launch, including the implementation of the early stage HTA. HTA brings the possibility of a social perspective as a supporting tool for evaluation. Although healthcare or welfare systems are not fully interconnected in many countries, information on costs and benefits in the broadest possible sense (both direct and indirect) can be taken into account and seen in the health system, welfare system, patient family, or national economy. Given the existing reimbursement systems, it is advisable to include the views of both stakeholders and take into account their objectives when deciding to support the selected medical technology.

"In the economic analysis, it is important to evaluate all the resources that are consumed when combining the effect of using the technology in question to address the given health problem" said the economic director. Possible costs are generally divided into direct medical, direct non-medical, and indirect in the HTA area (Table 7). The costs from public and private sources are evaluated so that it is possible to cover the whole society aspect of the benefit of the technology in question. 
Table 7. Type of costs.

\begin{tabular}{|c|c|c|}
\hline \multirow{4}{*}{ Direct costs } & Non-medical costs & $\begin{array}{l}\text { Time spent on the patient and his/her family-time spent } \\
\text { on unpaid work (e.g., housework), performed by the } \\
\text { patient or the family providing care. }\end{array}$ \\
\hline & \multirow{3}{*}{ Medical costs } & $\begin{array}{l}\text { Direct costs of the patient and his/her family-amounts } \\
\text { paid by the patient (including surcharges) for drugs, } \\
\text { medical devices, dental care, home care services. } \\
\text { Transport costs, nursing costs. Premiums paid to private } \\
\text { insurance companies and premiums paid by them. }\end{array}$ \\
\hline & & $\begin{array}{l}\text { Costs of public health insurance. } \\
\text { Drugs, medical devices and aids, diagnostic, therapeutic, } \\
\text { rehabilitation, spa, screening and preventive health care } \\
\text { covered by the general health insurance fund. } \\
\text { Prevention Fund of Public Health Insurance Companies. }\end{array}$ \\
\hline & & $\begin{array}{l}\text { Direct costs of the health system financed from other } \\
\text { public sources } \\
\text { Costs of the state budget, budget of regions, towns and } \\
\text { municipalities for the health system, which are thus paid } \\
\text { outside the system of public health insurance. }\end{array}$ \\
\hline \multirow[b]{2}{*}{ Non-direct costs } & & $\begin{array}{l}\text { Indirect costs of social security paid sickness benefits, } \\
\text { pensions, care allowances. }\end{array}$ \\
\hline & & $\begin{array}{l}\text { Productivity costs-loss of productivity due to the } \\
\text { reduced work capacity, short or long term absence at } \\
\text { work. Costs incurred by employers for recruiting and } \\
\text { training a worker to replace a patient. }\end{array}$ \\
\hline
\end{tabular}

\subsection{Qualitative Investigation-Evaluation of the Proposed Meddee Model}

In summary, the results of the interviews focused on feedback on the proposed model in the context of current business practice are described in Table 8.

Traditional concept approach describes how the situation and area is solved in the corporate environment now. Specifically, it is an expression of attitudes to the current setting of methodologies of the development stages in the company, the use of economic indicators, or to the lack of procedures at the theoretical level. "New concept approach" contains the statement of respondents in relation to the proposed methodology and the involvement of economic indicators in the given area, evaluation in relation to the current state of business.

Table 8. Evaluation of a new approach within a qualitative interview.

\begin{tabular}{|c|c|c|}
\hline Thematic Area & $\begin{array}{c}\text { Traditional Concept } \\
\text { Approach/Current State }\end{array}$ & New Concept Approach-Meddee \\
\hline $\begin{array}{l}\text { Description of the } \\
\text { process }\end{array}$ & $\begin{array}{l}\text { There is a methodology for the } \\
\text { development of medical devices in one } \\
\text { of the companies. } \\
\text { There is nothing like this in another } \\
\text { company, the initial idea is an estimate } \\
\text { of costs and development time, the } \\
\text { expected return is calculated, no other } \\
\text { methods are used. } \\
\text { At present in the MPS, in the Czech } \\
\text { Republic often dealt with randomly, } \\
\text { within the procedure of the given device } \\
\text { and its development, a generalized } \\
\text { methodology often does not exist. }\end{array}$ & $\begin{array}{l}\text { Setting and specification of stages of } \\
\text { development of medical devices, } \\
\text { determination of activities in each stage, } \\
\text { and related types of costs is considered } \\
\text { beneficial, it is necessary to specify in } \\
\text { practice, it is a suitable input and starting } \\
\text { point for setting up in the company. } \\
\text { It is a possibility to specify the estimates, for } \\
\text { real practice it would be appropriate to } \\
\text { automate processes, list other individual } \\
\text { tasks, go to a high level of detail. }\end{array}$ \\
\hline
\end{tabular}


Table 8. Cont.

\begin{tabular}{|c|c|c|}
\hline Thematic Area & $\begin{array}{c}\text { Traditional Concept } \\
\text { Approach/Current State }\end{array}$ & New Concept Approach-Meddee \\
\hline $\begin{array}{l}\text { Impact of the affected } \\
\text { technology on the } \\
\text { process }\end{array}$ & $\begin{array}{l}\text { From the point of view of business } \\
\text { practice, there is currently no } \\
\text { customized methodology in place for } \\
\text { the risk classes of a medical device or } \\
\text { other technology breakdown, } \\
\text { everything is modified in relation to a } \\
\text { new idea, innovative solutions. } \\
\text { From the theory point of view, } \\
\text { approaches are available, specifying the } \\
\text { phases of resource development, } \\
\text { focusing on the activities within each of } \\
\text { them, the focus lies, again with minimal } \\
\text { linkage to the type of technology. }\end{array}$ & $\begin{array}{l}\text { The model is beneficial from the point of } \\
\text { view of the simultaneous transition to new } \\
\text { legislation on new medical devices, taking } \\
\text { into account risk classes, cost links related } \\
\text { to increased registration fees. } \\
\text { To some extent, MedDee tries to capture the } \\
\text { nature of the solution, the type of } \\
\text { technology. This aspect is essential for } \\
\text { considering different business models. }\end{array}$ \\
\hline $\begin{array}{l}\text { Evaluation of the } \\
\text { investment effects on } \\
\text { the process }\end{array}$ & $\begin{array}{l}\text { - In financing decisions, different } \\
\text { business models are considered in } \\
\text { relation to the target group and the } \\
\text { method of financing, both being a key } \\
\text { input for calculating the return. } \\
\text { - In terms of economic methods, basic } \\
\text { profitability indicators or break-even } \\
\text { point calculations are included. It is } \\
\text { found to be sufficient. }\end{array}$ & $\begin{array}{l}\text { Evaluation of the investment includes } \\
\text { consideration of all possible forms of sales, } \\
\text { including the possibility of product } \\
\text { modification in relation to the target group } \\
\text { (medical facility or individualized solution } \\
\text { for users). This area is marginally presented } \\
\text { in the model and in the individual phases. } \\
\text { The work on the business model itself is } \\
\text { very complex, different in relation to the } \\
\text { target country, legislative conditions of } \\
\text { financing. It is one of the key places, it } \\
\text { opens up an area that could be addressed in } \\
\text { the future, there is also an interest from } \\
\text { companies, to contribute, and then to use all } \\
\text { the analyzed data. } \\
\text { Setting up a more detailed description of } \\
\text { the economic methods involved is } \\
\text { applicable, close to business practice, to the } \\
\text { requirements of approval authorities. }\end{array}$ \\
\hline $\begin{array}{l}\text { Potential cost savings } \\
\text { and potential risks }\end{array}$ & $\begin{array}{l}\text { The level of the current state of business } \\
\text { practice is such that the area is dealt } \\
\text { with in a relatively heterogeneous way, } \\
\text { in most Czech companies on the basis of } \\
\text { basic economic indicators of return or } \\
\text { calculation of the break-even point. } \\
\text { From the point of view of theory, it is } \\
\text { not often solved within the framework } \\
\text { of economic efficiency. } \\
\text { The situation is different when dealing } \\
\text { with a risk issue where aspects related } \\
\text { to the risk class are dealt with } \\
\text { intensively, in particular at the level of } \\
\text { approval authorities. }\end{array}$ & $\begin{array}{l}\text { The proposed methods make it possible to } \\
\text { compare the new solution with the } \\
\text { existing one. } \\
\text { Along with the setting of new legislative } \\
\text { conditions, it can be expected that pressure } \\
\text { will be increased to systematically specify } \\
\text { and evaluate savings and risks in relation to } \\
\text { the new product. }\end{array}$ \\
\hline Calculation of return & $\begin{array}{l}\text { Different types of rentability indicators, } \\
\text { more complex indicators are not } \\
\text { usually used. }\end{array}$ & $\begin{array}{l}\text { More complex evaluation methods } \\
\text { (CBA/CEA, HTA) are included in the new } \\
\text { model, but they are not addressed in terms } \\
\text { of business practice. } \\
\text { Given the ongoing legislative changes, it } \\
\text { can be assumed that even more complex } \\
\text { evaluations will become more and more } \\
\text { part of business practice. }\end{array}$ \\
\hline
\end{tabular}

From the above text, it is obvious that the proposed method of assessing the development of medical devices is understandable, but in current business practice, this level of detail is not methodologically discussed. Some phases are solved rather intuitively using basic economic indicators. 
The structure of the proposed MedDee approach is correct, phase specification corresponds to real processes, but in practice, it must be described at a higher level of detail. The economic methods included in the post-tests were known to the respondents in one of the companies, another group of the respondents in the framework of qualitative research gates judged them as above standard since they considered there would not be any time for their calculation. However, there is a consensus that there is an increasing need to describe all MD development processes, especially because new legislation comes into force and all companies will be forced to prepare for higher administrative burden and reporting.

\subsection{Economic Evaluation of the MD Development-A Case Study}

The economic assessment of the phases of the development of MDs is shown in the conditions of the Czech Republic, which ranks 19th among the EU countries in terms of GDP, which was USD 215.73 billion at the end of 2017. The annual wage level in 2017 was EUR 837 per month (the Czech Republic occupied the 20th place), and the EU average was EUR 1520. Inflation was 2.2\% [45]. The economic evaluation of the development of MDs is based on the evaluation of individual phases or activities within them (Table 9).

Table 9. Type of the costs in individual phases per a medical device of class IIb.

\begin{tabular}{|c|c|}
\hline Phase & Type of Costs \\
\hline Initiation & Wages \\
\hline Concept proposal & Wages \\
\hline Design and development & $\begin{array}{c}\text { Wages } \\
\text { Electrical safety (test costs in the accredited testing facility) } \\
\text { EUR 6000-12,000 } \\
\text { Biological evaluation EUR 4000-10,000 } \\
\text { Clinical testing EUR 2000-400,0001 } \\
\text { Type examination EUR 6000 thousand }\end{array}$ \\
\hline Verification and validation & $\begin{array}{c}\text { Wages } \\
\text { Conformity assessment EUR 14,000-20,000 thousand (Is, Im, Ir-EUR } \\
6000 \text {, for IIa/IIb EUR 14,000) }\end{array}$ \\
\hline Production & $\begin{array}{c}\text { Wages } \\
\text { Material } \\
\text { Output control (electrical MD—-production of own tester, for mechanical } \\
\text { MD—preparation and production of own test system) }\end{array}$ \\
\hline Market device deployment & $\begin{array}{l}\text { Wage per hour } \\
\text { Fee for patent filing (patent application in relation to the type of patent } \\
\text { protection-European, national, worldwide) }\end{array}$ \\
\hline
\end{tabular}

Table 5 mainly illustrates which types of costs are related to the process of MD development, where the financial margin is fundamentally influenced by the type of MD related to the risk class, and whether the company is able to secure things by itself (and therefore has relevant equipment). When solving the studies in the initiation and conception phase by own forces, these are the employees' internal wages. Payments for testing, certification, testing, and patent application are addressed in more rapid development phases. The key variable is clinical testing: the financial demands are high and the range is wide. Table 5 also corresponds to the conditions of the Czech Republic, where the wages per hour are in the range of CZK 300-650 per hour for an external professional of the Agreement on Working Conditions/Agreement on Work Activity or 30-50 thousand gross for a monthly wage. Figure 2 displays various processes that an MD must pass through before its market deployment. Certain approval processes are independent of each other, for example, the electrical safety examination can be performed independently in the clinical evaluation. The bottom part of the graph displays these processes running parallel in time with link-up when necessary. The upper section of the graph 
displays cumulative financial expenditures in time as they appear during the MD development. We assume that the obligation to pay the expenditures occurs immediately at the start of any given approval process-for its simplicity. It is necessary to assert that the costs associated with the clinical evaluation can be significantly higher in the case that they cannot be performed by the company (up to EUR 308 thousand). The costs associated with stages 1, 2, and 6 are not covered because they are highly dependent on a particular MD and company conditions, and thus highly varied (Figure 2).

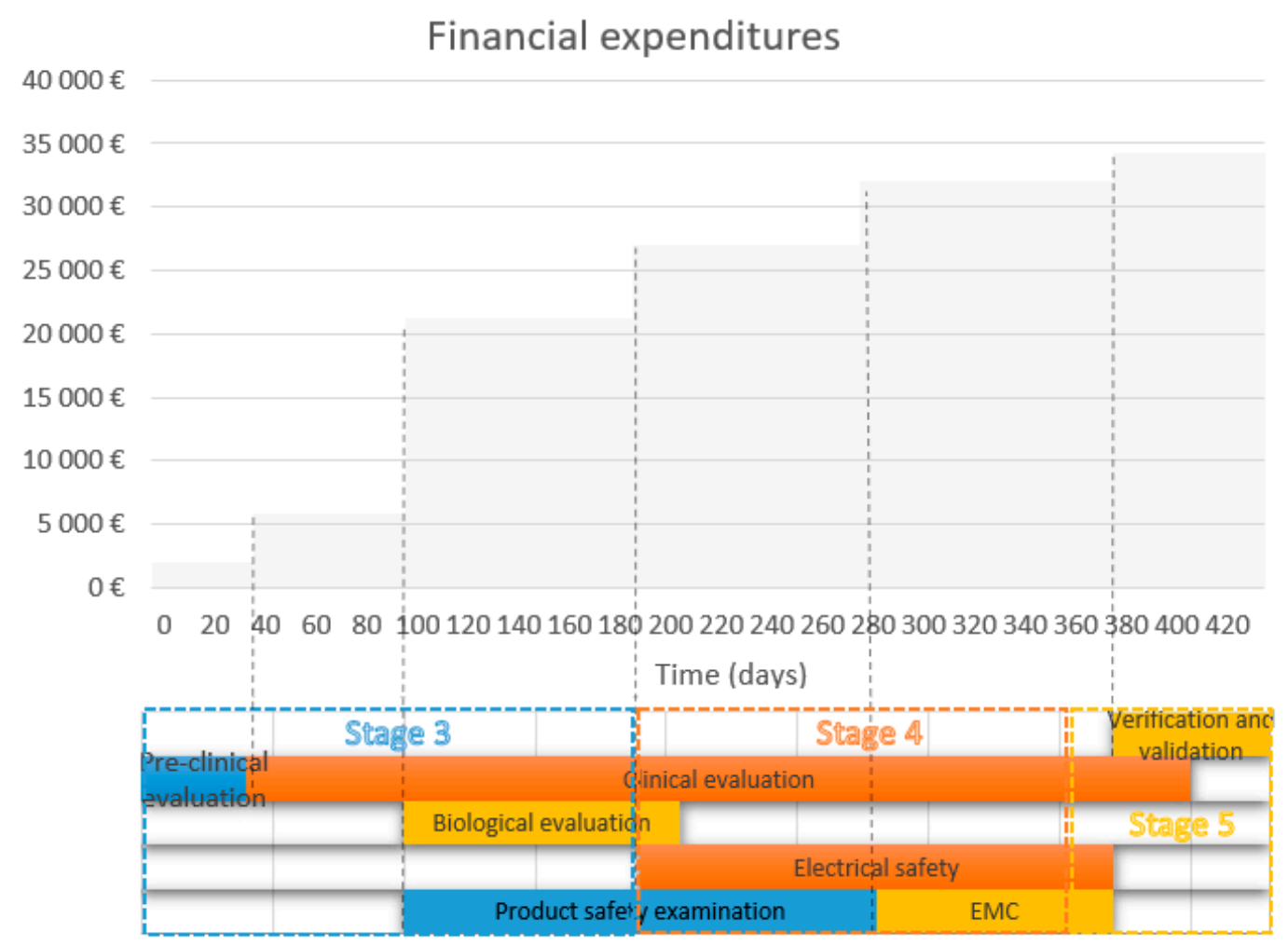

Figure 2. Financial expenditure during individual stages.

In view of the current situation in the Czech Republic and other European countries, the bottleneck for the medical devices and in vitro medical devices access to the common market is a lack of notified bodies (NB) to perform conformity assessment. It has been estimated by the European Commission that at the end of the year 2020, there will be at least 20 NBs covering all aspects of MDR and In-vitro diagnostic medical device regulation (IVDR). During summer 2019 some major NBs, that previously stated that they will seek accreditation according to the new legislation, and most notably the biggest notified body within the scope of in vitro diagnostic medical devices-Lloyd's Register QA had announced that it withdrew its services against Medical devices directive (MDD) and in-vitro diagnostic medical device directive (IVDD) and will not seek accreditation against MDR and IVDR framework. According to the European Commission website NANDO, there are currently(end of February 2020) only eleven accredited notified bodies under the MDR. This leaves the industry in unfavorable condition because of practice of the notified bodies to work preferably with large, established MD manufacturers first, leaving SME's—which make up $80 \%$ of the industry-without an immediate path to certification.

Another factor is practical nonexistence of the implementing acts for both regulations. It should be noted that even if everything goes according to the implementation rolling plan, there will be literally no time for the preparation for the industry, because the majority of the implementing acts were scheduled for the last quartile of 2019 or first quartile of 2020, which gives only 2-5 months for the implementation on the manufacturers side. This is a classic example of the bad case scenario, when the whole time of the transient period is taken up by authorities to prepare regulatory documentation 
and almost no time is left for their proper implementation, by industry. Another constraint in the MDR implementation is postponement of the operational status of the European Medical Devices Database (EUDAMED), despite the Commission previous repeated assurance that EUDAMED will be launched in stages.

In the field of in vitro diagnostics, the situation is far worse; some experts say that it is critical. As of February 2020, there are currently only three notified bodies, but one of them is located in the United Kingdom and its presence on the common market in the time of application of IVDR is uncertain. The in vitro diagnostic industry comprises circa 3000 companies and 40,000 products, most of them self-certified under IVDD, but it is estimated that 90 percent of those products will need a notified body certification under IVDR. The number of NBs seeking accreditation against IVDR is only 10. This indicates that the NBs will be subjected to 8 to 20 times higher workload than today. As in the scope of MDR, there is still a lot of work left on harmonization standards. The only hope is the fact that date of application of IVDR is the 26th of May 2022. Therefore, there is still little time to solve the situation.

\section{Discussion}

The authors have proposed the complexity model named MedDee, which comprises six phases: initiation, concept, design, production, final verification, and market deployment. The model is designed to a degree of detail to serve as the basis for estimating costs of development of MDs. In addition to the specification of the phases of development based on the knowledge ascertained both from theory and practice, the model also provides a societal perspective in economic methods for allocating the costs and benefits of its development. Thanks to the interviews conducted, it was clear and proven in practice what economic methods are being used at present, with what companies are confronted in terms of both approval authorities and future developments of the planned rules. Several activities within the device development process have been represented as models. Pietzsch et al. [18] constructed a model based on best-practice analysis and in-depth interviews. The results underline the significant differences between MD innovation and drug discovery and development. Soenksen [46] suggested a stage-gate model for life sciences where (i) general vision and investment strategy definition; (ii) venture search, screening, and rapid pre-evaluation; (iii) due diligence and negotiation of terms; and (iv) portfolio management, evaluation, and exit were included. Hede et al. [41] proposed a multifaceted conceptual framework with functions across the idea screening phase (Stage 2) up to the business and feasibility analysis phase (Stage 4). The principal objective of the proposed conceptual framework is to deliver a thorough assessment and a feasible roadmap. The proposed multifaceted framework, which entails the active participation of the multi-criteria hierarchical model for the product design, was evaluated to conduct a design optimization. In addition, this model considers technical parameters, and attempts to expand the scope to incorporate stakeholder's considerations such as increasing employment and investing in community welfare. Colomer-Farrarons used a case-study approach. This paper also examines the high-tech activities involved in the development of nano-enabled devices and describes the technology and innovation management process [3]. The research mentioned above describes the development of MDs and is already in relation to the current legislative state. Besides, this study demonstrates the financial complexity of the development of MDs concerning specific MED-type IIb costs. The baseline data and subsequent cost types make it possible to calculate the costs of various types of MD in different EU countries and describe how such an investment would affect cash and calculate the return. An important economic aspect related to the consideration and possible development of the proposal for the economic appreciation of the economic burden is the issue of discount rates. There is no general rule regarding discounts in healthcare. Some authors have recommended discount rates between $3 \%$ and $5 \%$ [47]; others have suggested a range between $2.5 \%$ and $8 \%$ [48]. Finally, the discount rates are expected to increase over time. Other distortions are, of course, due to the general phases of the model not relating to the type of MD in relation to risk. The estimated costs are for class IIb. In the framework of further research, the proposed model will be reviewed, and its use will be documented as an example of a case study. 
The benefit of the proposed model is the provision of information on the development of medical devices of wider professional publicity, given the know-how is often owned by companies and trade secrets. The authors provided a specification of the development phases, updated not only by adding these steps to the costs associated with these phases, but also by designing economic methods suitable for use during the development. The specification of this information was achieved through communication with representatives of companies who were willing during the interview to provide specific information on the costs of the individual phases in relation to the selected risk class. The methods were chosen with regard to the long-term approaches that should be accepted in the development of medical devices. Specifically, it is the HTA method, which is a comprehensive approach assessing the benefits of new technology from a societal perspective, using many economic indicators or other methods working with qualitative quantitative variables. It should be taken into account that this is a study carried out on a small medical device manufacturing company. The medical devices market is a regulated market from the perspective of both the Czech Republic and the EU, and regardless of the size of the company, everyone must meet their requirements. This study is based on real data of small firms dealing with design, development, and production of medical devices of class $\mathrm{I}-\mathrm{IIb}$. Costs may vary depending on the size of the business, but the individual processes and stages of design, development, production, and sales in the business and their need for funding are broadly the same regardless of the size of the business.

The authors recognize limitations of this framework such as the need for its validation, which will be undertaken in collaboration with our industrial partners, and the generality in its description. The marketing phase and after-sales tracking (PMS and PMCF) are not fully included in the model. The manufacturer's duty will now be more important than ever to set up the post-market monitoring processes for the profit of both non-clinical and especially clinical data. The manufacturer must provide a process to obtain the clinical data to help him/her evaluate the safety of the medical device. Considering that the PMCF process is not fully specified in either MDR 2017/745 or in the MEDDEV recommendation documents, the manufacturer should ideally follow ISO 14155 good clinical practice, which specifies all requirements for conducting both clinical trials and clinical studies. The PMCF process set up in this way is almost as expensive as the clinical trial itself. This investment should also be taken into account by the manufacturer and should be taken into account in the model. Because until now, manufacturers of the PMCF process have mostly dealt with PMS, when they most often evaluated the number of sold and reclaimed pieces, rarely relevant clinical data, from the perspective of small and medium-sized companies is not enough information on the financial cost of the PMCF process itself. This will be the subject of further studies, in particular in the transition to the new MDR. In addition, research will continue to create a system-dynamic model of the company, where it will be possible to calculate not only the return on investment, but also its overall impact on the financial health of the company.

\section{Conclusions}

Currently, the European manufacturers face the new Regulation (EU) 2017/745 (Regulation (EU) 2017/745 of the European Parliament and of the Council of 5 April 2017 on medical devices, amending Directive 2001/83/EC, Regulation (EC) No 178/2002 and Regulation (EC) No 1223/2009 and repealing Council Directives 90/385/EEC and 93/42/EEC (Text with EEA relevance), 2017) of the European Parliament and of the Council on Medical Devices (MDR), which will come into force in May 2020. New legislation will result in safety improvements, but the cost will be high (increased cost to the producer and thus to the health service provider), with some SMEs going out of business.

Companies are therefore under pressure to detect and update the development costs in a timely manner, which will change as a result of it.

The described MedDee model of the development of the MDs model attempts to react to this challenge which the companies are facing at the moment. In addition, this model provides an idea of the complexity of the required actions in relation to the individual phases and to the involvement 
of economic methods aimed at the evaluation of investment efficiency. Understanding the financial costs in relation to the MDD phases reduces the level of risk and uncertainty and makes it possible to obtain a realistic picture of the related financial expenditure. Furthermore, it provides constant key information for the right, tactical, and operational decisions about the development of the MD.

Author Contributions: Conceptualization, P.M., L.P., J.H., M.P., L.R., and M.A.; methodology, H.M., P.M., M.P. and M.A.; validation, H.T., P.M. and K.K.; formal analysis, H.M.; investigation, P.M., M.P. and M.A.; resources, H.M., P.M., L.R., H.M.,K.K. and B.K.; writing-original draft preparation, L.R., P.M. and B.K.; visualization, J.H..; supervision, K.K.; project administration, P.M., M.P., J.H.; funding acquisition, P.M., writing-original draft preparation all co authors. All authors have read and agreed to the published version of the manuscript.

Funding: This study was also supported by the research project The Czech Science Foundation (GACR) 2017 No. 17-03037S Investment evaluation of medical device development run at the Faculty of Informatics and Management, University of Hradec Kralove, Czech Republic.

Conflicts of Interest: The authors declare that they have no conflict of interest.

\section{Appendix A}

Table A1. Classification rules for medical devices.

\begin{tabular}{c}
\hline MD according to the Risk \\
\hline Class I-Provided sterile and/or have a \\
measuring function (low/medium risk) or \\
reusable low risk Class I devices placed on \\
the market in sterile condition, have a \\
measuring function, or are reusable surgical \\
instruments: Assessment of the technical \\
documentation relating only to those \\
specific features of the device, e.g., sterility, \\
measurement, or reprocessing.
\end{tabular}

Class IIa (medium risk) Class IIa devices: Assessment of the technical documentation for at least one representative device for each category of devices.

\section{Classification Rules}

Rule 1-Non-invasive devices.

Rule 2-Non-invasive devices intended for channelling or storing (now includes cells).

Rule 4-Non-invasive devices in contact with injured skin or mucous membrane.

Rule 5-Devices invasive in body orifices.

Rule 6-Surgically invasive devices for transient use.

Rule 10-Active devices for diagnosis and monitoring, emit ionising radiation.

Rule 11-Software intended to provide information used to make decisions with diagnosis or therapeutic purposes (from class I to class III).

Rule 13-All other active devices.

Rule 2-Non-invasive devices intended for channelling or storing (now includes cells).

Rule 3-Non-invasive devices that modify biological or chemical. composition of blood, body liquids, other liquids and cells.

Rule 4-Non-invasive devices in contact with injured skin or mucous membrane.

Rule 5-Devices invasive in body orifices.

Rule 6-Surgically invasive devices for transient use.

Rule 7-Surgically invasive devices for short-term use.

Rule 8-Surgically invasive devices for long-term use and implantable (including any device administering medicinal products, surgical mesh or spinal disc).

Rule 10-Active devices for diagnosis and monitoring, emit ionising radiation.

Rule 11-Software intended to provide information used to make decisions with diagnosis or therapeutic purposes (from class I to class III).

Rule 12-Active devices intended to administer and/or remove medicinal products, body liquids or other substances.

Rule 17-Devices specifically intended for recording of diagnostic images generated by $\mathrm{X}$-ray radiation.

Rule 19-Devices incorporating or consisting of nanomaterial.

Rule 20-Invasive devices with respect to body orifices to administer medicinal products by inhalation.

Rule 21-Substances or of combinations of substances that are intended to be introduced into the human body via a body orifice or applied to the skin and that are absorbed. 
Table A1. Cont.

MD according to the Risk

Class IIb (medium/high risk) Class IIb implantable devices (except sutures, staples, screws, wedges, plates, wires, pins, clips, and connectors) and class IIb active devices intended to administer and/or remove a medicinal product: Assessment of the technical documentation for every device. All other class IIb devices: Assessment of the technical documentation for at least one representative device per generic device group dental filings, dental braces, tooth crowns,

\section{Classification Rules}

Rule 2-Non-invasive devices intended for channelling or storing (now includes cells).

Rule 3-Non-invasive devices that modify biological or chemical composition of blood, body liquids, other liquids and cells. Rule 4-Non-invasive devices in contact with injured skin or mucous membrane.

Rule 5-Devices invasive in body orifices.

Rule 6-Surgically invasive devices for transient use.

Rule 7-Surgically invasive devices for short-term use.

Rule 8-Surgically invasive devices for long-term use and implantable (including any device administering medicinal products, surgical mesh or spinal disc).

Rule 9-Active therapeutic devices intended to exchange or administer energy.

Rule 10-Active devices for diagnosis and monitoring, emit ionising radiation.

Rule 11-Software intended to provide information used to make decisions with diagnosis or therapeutic purposes (from class I to class III).

Rule 12-Active devices intended to administer and/or remove medicinal products, body liquids, or other substances.

Rule 15-Contraception or prevention of the transmission of sexually transmitted diseases.

Rule 16-Specific disinfecting, cleaning, and rinsing devices. Rule 19-Devices incorporating or consisting of nanomaterial.

Rule 20-Invasive devices with respect to body orifices to administer medicinal products by inhalation.

Rule 21-Substances or of combinations of substances intended to be introduced into the human body via a body orifice or applied to the skin and that are absorbed.

Rule 2-Non-invasive devices intended for channelling or storing (now includes cells).

Rule 3-Non-invasive devices that modify biological or chemical composition of blood, body liquids, other liquids and cells.

Rule 6-Surgically invasive devices for transient use.

Rule 7-Surgically invasive devices for short-term use.

Rule 8-Surgically invasive devices for long-term use and implantable (including any device administering medicinal products, surgical mesh or spinal disc).

Rule 9-Active therapeutic devices intended to exchange or administer energy.

Rule 11-Software intended to provide information used to make decisions with diagnosis or therapeutic purposes (from class I to class III).

Class III (high risk). Class III devices: Assessment of the technical documentation for every device
Rule 14-Devices incorporating a medicinal substance including

human blood or plasma.

Devices used for contraception or prevention of sexually transmitted diseases.

Rule 15-Contraception or prevention of the transmission of sexually transmitted diseases.

Rule 18-Devices utilising non-viable tissues or cells of human origin or tissues of animal or derivatives.

Four new rules:

Rule 19-Devices incorporating or consisting of nanomaterial.

Rule 21-Substances or of combinations of substances intended to be introduced into the human body via a body orifice or applied to the skin and that are absorbed.

Rule 22-Active therapeutic devices with an integrated or incorporated diagnostic function that significantly determines the patient management. 


\section{References}

1. Lee, M.; Yoon, Y.; Ryu, G.H.; Bok, H.S.; Yoon, K.; Park, S.; Lee, K.-S. Innovative Distribution Priorities for the Medical Devices Industry in the Fourth Industrial Revolution. Int. Neurourol. J. 2018, 22, S83-S90. [CrossRef]

2. Lee, M.; Park, S.; Lee, K.-S. What are the features of successful medical device start-ups? Evidence from KOREA. Sustainability 2019, 11, 1948. [CrossRef]

3. Juanola-Feliu, E.; Colomer-Farrarons, J.; Miribel-Català, P.; Samitier, J.; Valls-Pasola, J. Market challenges facing academic research in commercializing nano-enabled implantable devices for in-vivo biomedical analysis. Technovation 2012, 32, 193-204. [CrossRef]

4. Vernon, J.A.; Goldberg, R.; Golec, J. Economic Evaluation and Cost-Effectiveness Thresholds: Signals to Firms and Implications for R\&D Investment and Innovation. Pharmacoeconomics 2009, 27, 797-806. [PubMed]

5. Freiberg, F.; Scholz, P. Evaluation of Investment in Modern Manufacturing Equipment Using Discrete Event Simulation. Procedia Econ. Financ. 2015, 34, 217-224. [CrossRef]

6. Kiliç, M.; Kaya, İ. The prioritisation of provinces for public grants allocation by a decision-making methodology based on type-2 fuzzy sets. Urban Stud. 2016, 53, 755-774. [CrossRef]

7. Vallejo-Torres, L.; Steuten, L.; Parkinson, B.; Girling, A.J.; Buxton, M.J. Integrating Health Economics Into the Product Development Cycle: A Case Study of Absorbable Pins for Treating Hallux Valgus. Med. Decis. Mak. 2011, 31, 596-610. [CrossRef]

8. Money, A.G.; Barnett, J.; Kuljis, J.; Craven, M.P.; Martin, J.L.; Young, T. The role of the user within the medical device design and development process: medical device manufacturers' perspectives. BMC Med. Inf. Decis. Mak. 2011, 11, 15. [CrossRef]

9. IJzerman, M.J.; Koffijberg, H.; Fenwick, E.; Krahn, M. Emerging Use of Early Health Technology Assessment in Medical Product Development: A Scoping Review of the Literature. Pharmacoeconomics 2017, 35, 727-740. [CrossRef]

10. Johal, S.S.; Oliver, P.; Williams, H.C. Better decision making for evaluating new medical device projects: A real options approach. J. Med. Mark. 2008, 8, 101-112. [CrossRef]

11. MacKeigan, L.D.; Bootman, J.L. A Review of Cost-Benefit and Cost-Effectiveness Analyses of Clinical Pharmacy Services. J. Pharm. Mark. Manag. 1988, 2, 63-84. [CrossRef] [PubMed]

12. Danner, M.; Hummel, J.M.; Volz, F.; van Manen, J.G.; Wiegard, B.; Dintsios, C.-M.; Bastian, H.; Gerber, A.; IJzerman, M.J. Integrating patients' views into health technology assessment: Analytic hierarchy process (AHP) as a method to elicit patient preferences. Int. J. Technol. Assess. Health Care 2011, 27, 369-375. [CrossRef] [PubMed]

13. Akoka, J.; Leune, B.; Koster, A. An expert system for feasibility assessment of product development. Expert Syst. Appl. 1994, 7, 291-303. [CrossRef]

14. Winterhalter, S.; Zeschky, M.B.; Neumann, L.; Gassmann, O. Business Models for Frugal Innovation in Emerging Markets: The Case of the Medical Device and Laboratory Equipment Industry. Technovation 2017, 66-67, 3-13. [CrossRef]

15. Ball, G.P.; Shah, R.; Donohue, K. The decision to recall: A behavioral investigation in the medical device industry. J. Oper. Manag. 2018, 62, 1-15. [CrossRef]

16. Martin, J.L.; Clark, D.J.; Morgan, S.P.; Crowe, J.A.; Murphy, E. A user-centred approach to requirements elicitation in medical device development: a case study from an industry perspective. Appl. Ergon. 2012, 43, 184-190. [CrossRef]

17. Panescu, D. Medical device development. In Proceedings of the 2009 Annual International Conference of the IEEE Engineering in Medicine and Biology Society, Minneapolis, MN, USA, 2-6 September 2009; pp. 5591-5594.

18. Pietzsch, J.B.; Shluzas, L.A.; Paté-Cornell, M.E.; Yock, P.G.; Linehan, J.H. Stage-Gate Process for the Development of Medical Devices. J. Med. Devices 2009, 3, 021004. [CrossRef]

19. Tomaskova, H.; Maresova, P.; Penhaker, M.; Augustynek, M.; Klimova, B.; Fadeyi, O.; Kuca, K. The Business Process Model and Notation of Open Innovation: The Process of Developing Medical Instrument. Open Innov. Technol. Mark. Complex. 2019, 5, 101. [CrossRef]

20. Medina, L.A.; Kremer, G.E.O.; Wysk, R.A. Supporting medical device development: a standard product design process model. J. Eng. Des. 2013, 24, 83-119. [CrossRef] 
21. Shah, S.G.S.; Robinson, I.; AlShawi, S. Developing medical device technologies from users' perspectives: A theoretical framework for involving users in the development process. Int. J. Technol. Assess. Health Care 2009, 25, 514-521. [CrossRef]

22. Songkajorn, Y.; Thawesaengskulthai, N. Medical Device Innovation Development Process. Int. J. Innov. Technol. Manag. 2014, 11, 1450027. [CrossRef]

23. Korol, T. Early warning models against bankruptcy risk for Central European and Latin American enterprises. Econ. Model. 2013, 31, 22-30. [CrossRef]

24. Sun, J.; Shang, Z.; Li, H. Imbalance-oriented SVM methods for financial distress prediction: a comparative study among the new SB-SVM-ensemble method and traditional methods. J. Oper. Res. Soc. 2014, 65, 1905-1919. [CrossRef]

25. Ashby, R.L.; Gabe, R.; Ali, S.; Saramago, P.; Chuang, L.-H.; Adderley, U.; Bland, J.M.; Cullum, N.A.; Dumville, J.C.; Iglesias, C.P.; et al. VenUS IV (Venous leg Ulcer Study IV)—Compression hosiery compared with compression bandaging in the treatment of venous leg ulcers: a randomised controlled trial, mixed-treatment comparison and decision-analytic model. Health Technol. Assess. 2014, 18, 1-294. [CrossRef] [PubMed]

26. Downing, A.; Morris, E.J.; Corrigan, N.; Sebag-Montefiore, D.; Finan, P.J.; Thomas, J.D.; Chapman, M.; Hamilton, R.; Campbell, H.; Cameron, D.; et al. High hospital research participation and improved colorectal cancer survival outcomes: a population-based study. Gut 2017, 66, 89-96. [CrossRef] [PubMed]

27. Heintz, U.; Schlichting, I. Blue light-induced LOV domain dimerization enhances the affinity of Aureochrome 1a for its target DNA sequence. eLife 2016, 5, e11860. [CrossRef]

28. Castañeda-Orjuela, C.; García-Molina, M.; De la Hoz-Restrepo, F. Is There Something Else Beyond Cost-Effectiveness Analysis for Public Health Decision Making? Value Health Reg. Issues 2020, 23, 1-5. [CrossRef]

29. Dozet, A.; Ivarsson, B.; Eklund, K.; Klefsgård, R.; Geijer, M. Radiography on wheels arrives to nursing homes - an economic assessment of a new health care technology in southern Sweden: Mobile radiography in nursing homes. J. Eval. Clin. Pract. 2016, 22, 994-1001. [CrossRef]

30. Brockis, E.; Marsden, G.; Cole, A.; Devlin, N. A Review of NICE Methods Across Health Technology Assessment Programmes: Differences, Justifications and Implications. OHE 2016, 16, 3-37.

31. Mathes, T.; Jacobs, E.; Morfeld, J.-C.; Pieper, D. Methods of international health technology assessment agencies for economic evaluations-A comparative analysis. BMC Health Serv. Res. 2013, 13, 371. [CrossRef]

32. Hartz, S.; John, J. Contribution of economic evaluation to decision making in early phases of product development: A methodological and empirical review. Int. J. Technol. Assess. Health Care 2008, 24, 465-472. [CrossRef]

33. McAteer, H.; Cosh, E.; Freeman, G.; Pandit, A.; Wood, P.; Lilford, R. Cost-effectiveness analysis at the development phase of a potential health technology: examples based on tissue engineering of bladder and urethra. J. Tissue Eng. Regen. Med. 2007, 1, 343-349. [CrossRef] [PubMed]

34. Girling, A.; Young, T.; Brown, C.; Lilford, R. Early-Stage Valuation of Medical Devices: The Role of Developmental Uncertainty. Value Health 2010, 13, 585-591. [CrossRef] [PubMed]

35. Fotr, J. Podnikatelský Plán a Investiční Rozhodování; Grada: Prague, Czech Republic, 1999; ISBN 978-80-7169-812-8.

36. Kotler, P. Marketing Management: Analysis, Planning, Implementation, and Control; Prentice-Hall: Upper Saddle River, NJ, USA, 1991; ISBN 978-0-13-552480-0.

37. EU Medical Device Regulation. Available online: https://www.tuv-sud.com/industries/medical-deviceshealthcare/market-approval-amp-certification/eu-market-access/eu-medical-device-regulation (accessed on 25 December 2018).

38. Paul Brooks Medical Device Regulation: What's the Impact on Notified Bodies? Available online: https:// www.med-technews.com/features/medical-device-regulation-whats-the-impact-on-notified-bodi/ (accessed on 13 December 2018).

39. Bernasconi, S. How MDR and IVDR Are Reshaping Europe's Medtech Industry; Pulse of the Industry 2017; EY-Ernst Young: Durham, NC, USA, 2017; pp. 28-29.

40. EUCOMED. Medical Technology Financial Impact of the Revision of the EU Medical Devices Directives on European SMEs and Industry; New Medtech Regulations; MedTechEurope: Granada, Spain, 2013; p. 3.

41. Hede, S.; Nunes, M.J.L.; Ferreira, P.F.V.; Rocha, L.A. Incorporating sustainability in decision-making for medical device development. Technol. Soc. 2013, 35, 276-293. [CrossRef] 
42. Adams, W.C. Conducting Semi-Structured Interviews. In Handbook of Practical Program Evaluation; Newcomer, K.E., Hatry, H.P., Wholey, J.S., Eds.; John Wiley \& Sons, Inc.: Hoboken, NJ, USA, 2015; pp. 492-505. ISBN 978-1-119-17138-6.

43. Regulation (EU) 2017/745 of the European Parliament and of the Council of 5 April 2017 on Medical Devices, Amending Directive 2001/83/EC, Regulation (EC) No 178/2002 and Regulation (EC) No 1223/2009 and Repealing Council Directives 90/385/EEC and 93/42/EEC (Text with EEA Relevance.); European Commission: Brussels, Belgium, 2017; Volume 117.

44. Shah, S.G.S.; Robinson, I. Benefits of and barriers to involving users in medical device technology development and evaluation. Int. J. Technol. Assess. Health Care 2007, 23, 131-137. [CrossRef] [PubMed]

45. Home-Eurostat. Available online: https://ec.europa.eu/eurostat (accessed on 25 December 2018).

46. Soenksen, L.R.; Yazdi, Y. Stage-gate process for life sciences and medical innovation investment. Technovation 2017, 62-63, 14-21. [CrossRef]

47. Smith, D.; Gravelle, H. The Practice of Discounting Economic Evaluation of Health Care Interventions; CHE Technical Paper Series 19; The University of York: York, UK, 2000.

48. Wright, D. Discount Rate; York Health Economics Consortium: York, UK, 2016.

(C) 2020 by the authors. Licensee MDPI, Basel, Switzerland. This article is an open access article distributed under the terms and conditions of the Creative Commons Attribution (CC BY) license (http://creativecommons.org/licenses/by/4.0/). 